\title{
Cloning, Expression and Structural Modeling of the MlrA Protein from Novosphingobium sp. KKU25s for Microcystin Degradation
}

\author{
Kranokpron MOOLWANG ${ }^{1,2}$, Sakda DADUANG ${ }^{1,3}$, \\ Thidarat SOMDEE ${ }^{4}$ and Theerasak SOMDEE ${ }^{1,2, *}$
}

${ }^{I}$ Protein and Proteomics Research Center for Commercial and Industrial Purposes, Khon Kaen University, Khon Kaen 40002, Thailand

${ }^{2}$ Department of Microbiology, Faculty of Science, Khon Kaen University, Khon Kaen 40002, Thailand

${ }^{3}$ Faculty of Pharmaceutical Sciences, Khon Kaen University, Khon Kaen 40002, Thailand

${ }^{4}$ Faculty of Public Health, Mahasarakham University, Mahasarakham 44150, Thailand

('Corresponding author's e-mail: thesom@kku.ac.th)

Received: 31 January 2020, Revised: 16 December 2020, Accepted: 23 December 2020

\begin{abstract}
MlrA is a gene involved in the degradation of toxic cyanobacterial microcystins. This gene encodes microcystinase, mlrA, the $1^{\text {st }}$ enzyme in the pathway that breaks down toxic cyanobacterial microcystins. In this study, primers were designed, and polymerase chain reaction (PCR) was performed to amplify the mlrA gene in Novosphincgobium sp. KKU25s. A PCR product of 752 base pairs was obtained. The nucleotide sequence of the mlrA gene of Novosphingobium sp. KKU25s was similar to that of Sphingomonas sp. ACM-3962 (98\% similarity). The mlrA gene of Novosphingobium sp. KKU25s was further cloned into the pGEM T-Easy plasmid to obtain the nucleotide sequence of the mlrA gene. The gene was also ligated into the pET32a plasmid for gene expression. Expression was induced by isopropyl $\beta$-D-1-thiogalactopyranoside (IPTG) and verified using SDS-PAGE. The expressed protein was approximately 22 kilodaltons. The cell-free extract $(\mathrm{CE})$ containing the crude protein from confirmed recombinant cells showed high activity in the biodegradation of [Dha $\left.{ }^{7}\right]$ MC-LR. [Dha ${ }^{7}$ MC-LR at an initial concentration of $30 \mathrm{mg} \mathrm{L}^{-1}$ and was completely biodegraded within $30 \mathrm{~h}$. A distinct product derived from $\left[\mathrm{Dha}^{7}\right]$ MC-LR appeared with a decrease in the [Dha $\left.{ }^{7}\right] \mathrm{MC}-\mathrm{LR}$ peak in the HPLC profile. The product $\left(\mathrm{m} / \mathrm{z}\right.$ 999.51) showed a molecular weight of 18 , which is higher than that of native [Dha ${ }^{7}$ MC-LR $\left(\mathrm{m} / \mathrm{z}\right.$ 981.50), and was determined to be a linearized peptide fragment of [Dha ${ }^{7}$ ] MC-LR using LC-MS analysis. The 3-dimensional structure of microcystinase was predicted from the amino acid sequence deduced from the mlrA gene by the Swiss Model and Phyre2 programs. The structure contained a predicted alpha helix. The predicted 3-dimensional structure was also similar to that of a protein in the CAAX protease group.
\end{abstract}

Keywords: Microcystin, MlrA protein, Microcystinase, Cloning, Expression, Structural modeling

\section{Introduction}

The most frequently occurring and widespread cyanotoxins are microcystins (MCs). They are a family of monocyclic heptapeptide hepatotoxins produced by various genera of freshwater cyanobacteria, such as Microcystis, Anabaena, Oscillatoria (Planktothrix), Nostoc, and Anabaenopsis [1]. Toxins have become aquatic environmental problems worldwide because they primarily affect the liver, causing minor to widespread damage to animals and humans depending on the amount of toxin absorbed [2]. MCs are typically toxic because they inhibit the activities of protein phosphatases 1 and $2 \mathrm{~A}$ and cause chronic or 
acute poisoning, liver failure and liver tumor promotion in humans and animals [3]. In 1996, 53 patients died at a hemodialysis center in Brazil as a result of acute liver failure [4].

MCs are chemically stable over a wide range of temperatures and $\mathrm{pH}$ values, and in the presence of various bacterial enzymes, which is probably due to their cyclic structure [5]. Dissolved MCs have been documented as being highly resistant to conventional water treatment processes [6]. Therefore, many drinking water treatment plants are ineffective in the complete degradation of MCs. A combination of sophisticated water treatments, such as coagulation, chlorination, adsorption with activated carbon and ozonation, can reduce the concentration of MCs, however, during cyanobacterial blooms, water treatment plants can become overwhelmed [7,8].

Biodegradation is a safe and natural treatment for removing MCs from water. This method involves indigenous bacteria and complex communities of microorganisms in lake water $[9,10]$. This microbial process can reduce both intracellular toxins within cyanobacterial cells and extracellular toxins released into water bodies [6]. Lakes with a history of cyanobacterial blooms containing MCs may have indigenous bacteria that are capable of using cyanobacterial cells and MCs as a food source and rapidly degrading toxins [11]. Many studies have reported the degradation of MCs by natural bacteria [12]. Bacterial strains have been reported to degrade MCs [13]. In addition, several research studies have been successful in characterizing the enzymatic pathway of MC degradation, which involves intermediate byproducts and MC-degrading gene clusters in Sphingomonas sp. It was found that microcystinase, or the MlrA protein, is the $1^{\text {st }}$ and most important enzyme cleaving highly stable cyclic peptides into linear MCs, whose toxic activity is reduced 160 -fold compared with that of the parent MCs. When the cyclic peptide is opened, the remaining peptide is easily cleaved by the other enzyme to form a small peptide (MlrB, MlrC and MlrD proteins) [14,15].

In Thailand, there have been several reports of $\mathrm{MC}$ contamination in water [16-20]. One of the $1^{\text {st }}$ investigations was conducted at the Mae Kuang Dam, Chaingmai Province, during April 2000 and March 2001, and this study reported increased levels of MC-LR and MC-RR [17]. This research has led to additional studies on MC degradation in Thailand. When the presence of MCs in scum and water was determined in samples collected from a giant freshwater prawn farm in Chiang Rai Province, MC-LR and -RR were found to be the dominant MC types. Based on the results of these studies, MC production was suggested to present a risk of MC accumulation in bodies of water in Thailand [17,21]. Enzyme-linked immunosorbent assays specific for cyanotoxins were performed to detect and quantify MCs as well as cylindrospermopsins; the highest average MC content $\left(0.913 \mu \mathrm{gL}^{-1}\right)$ was found in a sample collected from Bueng Nong Khot, and the highest average cylindrospermopsin content $\left(0.463 \mu \mathrm{gL}^{-1}\right)$ was found in a sample collected from Bueng See Than. Previously, an MC-degrading bacterium was isolated from a pond in Khon Kaen Province, Thailand [10]. It was classified as Novosphingobium sp. strain KKU25s. In this study, molecular biology and proteomics methods, including cloning, gene expression and 3D structural analysis, were used to characterize the mlrA enzyme, which is involved in the degradation of MCs and encoded by the mlrA gene. Knowledge from this study can be applied in the development of $\mathrm{MC}$ degradation processes in future studies.

\section{Materials and methods}

\section{Source of $\left[\mathrm{Dha}^{7}\right]$ MC-LR}

A large mass of Microcystis aeruginosa cell material was collected from the Bueng Nong Khot reservoir, Khon Kaen, Thailand. The material was extracted and purified using the method described by Somdee et al. [9]. Liquid chromatography mass spectrometry (LC-MS) analysis was performed to further identify the purified toxin, and high-performance liquid chromatography (HPLC) analysis was conducted to determine the yield and purity.

\section{Strain, vectors and host cell}

The bacterial strain Novosphingobium sp. KKU25s, which was able to degrade [Dha ${ }^{7}$ ] MC-LR [10], was used in the present study. The strain was cultured in peptone yeast extract medium (PYEM; $10 \mathrm{~g}$ of 
peptone and $5 \mathrm{~g}$ of yeast extract per liter; at $\mathrm{pH}$ 7.2) in a shaking incubator at $180 \mathrm{rpm}$ and $30^{\circ} \mathrm{C}$. The cloning vector pGEM-T easy and the prokaryotic expression vector pET32a were purchased from the Promega Corporation. Escherichia coli DH5 $\alpha$ and Escherichia coli BL21 (DE3) were used as host strains for cloning and expression, respectively. Both were cultured in Luria-Bertani (LB) medium at $37^{\circ} \mathrm{C}$ with shaking at $200 \mathrm{rpm}$.

\section{Amplification of the mlrA gene}

The mlrA gene was amplified by PCR with Novosphingobium sp. KKU25s genomic DNA as the template. Genomic DNA was extracted according to Doyle and Doyle [22]. Primers specific to the conserved sequence of mlrA, which was deposited in GenBank, were used to obtain a partial sequence of mlrA in Novosphingobium sp. KKU25s (Table 1). PCR was performed in a PTC-200 Peltier thermal cycler (MJ Research, USA) in a $25 \mu \mathrm{L}$ reaction containing 1xGoTaq ${ }^{\circledR}$ GreenMaster Mix (Promega, USA), $1 \mathrm{mM} \mathrm{MgCl}$ (Promega, USA), each primer at $0.5 \mu \mathrm{M}$ (Invitrogen, USA) and $20 \mathrm{ng}$ of genomic DNA. The PCR amplification protocol was as follows: initial denaturation at $94{ }^{\circ} \mathrm{C}$ for 1 min followed by 30 cycles of DNA denaturation at $94{ }^{\circ} \mathrm{C}$ for $1 \mathrm{~min}$, primer annealing at $50{ }^{\circ} \mathrm{C}$ for $1 \mathrm{~min}$, and strand extension at $72{ }^{\circ} \mathrm{C}$ for $3 \mathrm{~min}$. After cycling, a final extension step was performed at $72{ }^{\circ} \mathrm{C}$ for $10 \mathrm{~min}$. To confirm reproducibility, PCR was carried out in triplicate. Sterile water was used as the template for the negative control, which was run in parallel. PCR products of the expected size were analyzed via $1.5 \%$ agarose gel electrophoresis with SYBR Green I staining (Invitrogen, USA).

Table 1 Primer design and PCR product sizes.

\begin{tabular}{cccccc}
\hline Primer & Base & $\begin{array}{c}\mathbf{\%} \\
\mathbf{G C}\end{array}$ & $\begin{array}{c}\mathbf{\%} \\
\mathbf{T}_{\mathbf{m}}\end{array}$ & $\begin{array}{c}\text { Corresponding to } \\
\text { mlrA gene base\# }\end{array}$ & $\begin{array}{c}\text { Product } \\
\text { size } \\
\text { (bp) }\end{array}$ \\
\hline Primer 1. F = GATCCCGCTGTCAGGTCTACGTTCGAG & 28 & 61 & 65.8 & $159-180$ & 752 \\
R = CTCGAGCCTCCCCACAAATCAGGACGA & 27 & 59 & 64.3 & $910-890$ & \\
Primer 2. F = GGATCCATCGCTGCTACTCAGCCCTG & 26 & 62 & 64.3 & $483-502$ & 310 \\
R = CTCGAGGTTATGGATGGCGTGAGTGA & 26 & 54 & 61.1 & $792-773$ & 1008 \\
Primer 3. F = GGATCCATGCGGGAGTTTGTCAAAC & 25 & 52 & 59.3 & $1-19$ & $1008-990$ \\
R = CTCGAGCGCGTTCGCGCCGGACTTG & 25 & 72 & 67.5 & & \\
*F= FORWARD PRIMER **R = REVERSE PRIMER & & & & \\
\hline
\end{tabular}

\section{Cloning and sequencing of the mlrA gene}

The target band was excised from the gel and purified using a Gel Elution Kit (Bioactive Co., Ltd., USA) according to the manufacturer's protocol and ligated into the cloning pGEM-T easy vector. The recombinant $\mathrm{pGEM}-\mathrm{T}$ vector was easily digested using the restriction enzymes BamHI and XhoI. The fragments were ligated into the expression vector $\mathrm{pET} 32 \mathrm{a}$, which was then transformed into E. coli $\mathrm{DH} 5 \alpha$. The ligation reaction was conducted in a mixture consisting of $3 \mu$ Lof $2 \mathrm{x}$ rapid ligation buffer, 1 $\mu \mathrm{L}$ of the pGEM-T Easy vector $(50 \mathrm{ng}), 3 \mu \mathrm{L}$ of the PCR product, $1 \mu \mathrm{L}$ of T4 DNA ligase and deionized water to a final volume of $10 \mu \mathrm{L}$, and the mixture was incubated at $4{ }^{\circ} \mathrm{C}$ overnight. The ligated product was then transformed into competent E. coli BL21 (DE3) cells according to the standard heat-shock protocol [23]. The cells were grown on LB agar plates supplemented with ampicillin $\left(100 \mathrm{mg} \mathrm{mL}^{-1}\right)$ and chloramphenicol $\left(34 \mu \mathrm{g} \mathrm{mL}^{-1}\right)$, and 4 positive recombinant clones containing the mlrA gene were selected by blue-white spot screening and verified by colony PCR. The nucleotide sequencing of positive recombinant clones was carried out by $1^{\text {st }}$ Base Laboratories, Singapore (Ward Medic Ltd.). Then, the sequence data were analyzed with BLASTn at NCBI GenBank (https://www.ncbi.nlm.nih.gov), and multiple sequence alignments were constructed using MEGA6 software. 


\section{Recombinant expression}

The recombinant bacteria containing the mlrA gene (KKU25s-mlrA recombinant) were cultured in LB broth medium supplemented with ampicillin $(50 \mu \mathrm{g} / \mathrm{mL})$ at $37{ }^{\circ} \mathrm{C}$ with shaking at $180 \mathrm{rpm}$. The cultures were grown until the optical density at $600 \mathrm{~nm}\left(\mathrm{OD}_{600}\right)$ reached 0.6 . Then, the expression of the mlrA gene was induced with isopropyl $\beta$-D-1 thiogalactopyranoside (IPTG) at a final concentration of 1 $\mathrm{mM}$, and the cultures were incubated overnight. Cells were harvested by centrifugation at $12,000 \mathrm{~g}$ for 20 min at $4{ }^{\circ} \mathrm{C}$ and resuspended in a $50 \mathrm{mM}$ phosphate-buffered solution (PBS, pH 7.3), which was repeated 3 times. The pellet was disrupted by ultrasonication with an ultrasonic Processor (VCX 130, SONICS) three times for $30 \mathrm{~s}$ each at $40 \%$ of maximal power, on ice, followed by centrifugation at $12,000 \mathrm{~g}$ for 20 min at $4{ }^{\circ} \mathrm{C}$. The supernatant was analyzed by SDS-PAGE in a $15 \%$ polyacrylamide gel [24].

\section{MC degradation by recombinant bacteria}

After sonication, the cell-free extract (CE) containing the crude protein from recombinant cells was used to degrade MCs. CE was added to a test tube containing PBS buffer (pH 7.3) and [Dha ${ }^{7}$ MC-LR (30 $\mathrm{mg} \mathrm{L}^{-1}$ ). The tubes were incubated at $30^{\circ} \mathrm{C}$ at $200 \mathrm{rpm}$. Hydrochloric acid was added to stop the reaction, and samples were taken at reaction times of $0,6,12,18$ and $24 \mathrm{~h}$. The harvested samples were centrifuged, and the supernatant was analyzed by HPLC and LC-MS.

\section{HPLC and LC-MS for MC degradation analysis}

High-performance liquid chromatography (HPLC) was used to analyze MC degradation by the recombinant cell-free extract (CE). HPLC was performed using the following components: A 600-pump controller, a 717 plus autosampler and a 2,487 dual absorbance detector (Waters, USA). The column was a C18 TSK-gel ODS-80Ts Column (Toyopeal, Japan; 150 $\times 4.6 \mathrm{~mm}^{2}$ ). The mobile phase was acetonitrile:0.05 M phosphate buffer $\mathrm{pH} 3.0$ at a ratio of 30:70 (v/v) supplied at a flow rate of $1 \mathrm{~mL} \mathrm{~min}^{-1}$. The wavelength was measured at $238 \mathrm{~nm}$ (UV Detector).

The LC-MS system consisted of a Waters Alliance 2,695 liquid chromatograph with a diode array detector (Waters, USA) and a Q-TOF (quadrupole mass filter-time-of-flight) mass spectrometer with a Zspray ES (electrospray) source (Micromass, UK). A $5 \mu \mathrm{m}, 3.9 \times 150 \mathrm{~mm}^{2}$ Symmetry $\mathrm{C}_{18}$ column (Waters, USA) was used to separate the toxins. The mobile phase consisted of acetonitrile (solvent A) and $0.1 \%$ $(\mathrm{v} / \mathrm{v})$ formic acid in water (solvent B). The HPLC effluent was delivered to the Z-spray ES source of a Micromass Q-TOF 2 hybrid quadrupole time-of-flight mass spectrometer (Micromass, UK). The capillary and conevoltages were $3.00 \mathrm{kV}$ and $30 \mathrm{~V}$, respectively. MassLynxNT software, version 4.0 (Micromass, UK), was used to perform data acquisition and processing. The LC system was directly connected to an MS instrument without stream splitting.

\section{Three-dimensional structure modeling}

Predicted 3-dimensional (3D) models were constructed using the SWISS-MODEL server and the automated protein homology-modeling server at ExPASy (Switzerland; (http://swiss model.expasy.org/). The model was generated using the amino acid sequence deduced from the nucleotide sequence of mlrA with activity. The 3-dimensional models were compared with the PHYRE2 Protein Recognition Engine V 2.0 server (http://www.sbg.bio.ic.ac.uk/ phyre2/html/page. cgiId.= index).

\section{Results and discussion}

\section{Amplification of the mlrA gene}

Primers specific for the mlrA gene of Novosphingobium sp. KKU25s were designed. The PCR amplification results showed that the $1^{\text {st }}$ primer yielded a PCR product of 752 base pairs (Figure 1), whereas the $2^{\text {nd }}$ primer provided a PCR product of 310 base pairs, and the third primer yielded a PCR product of 1,008 base pairs. 


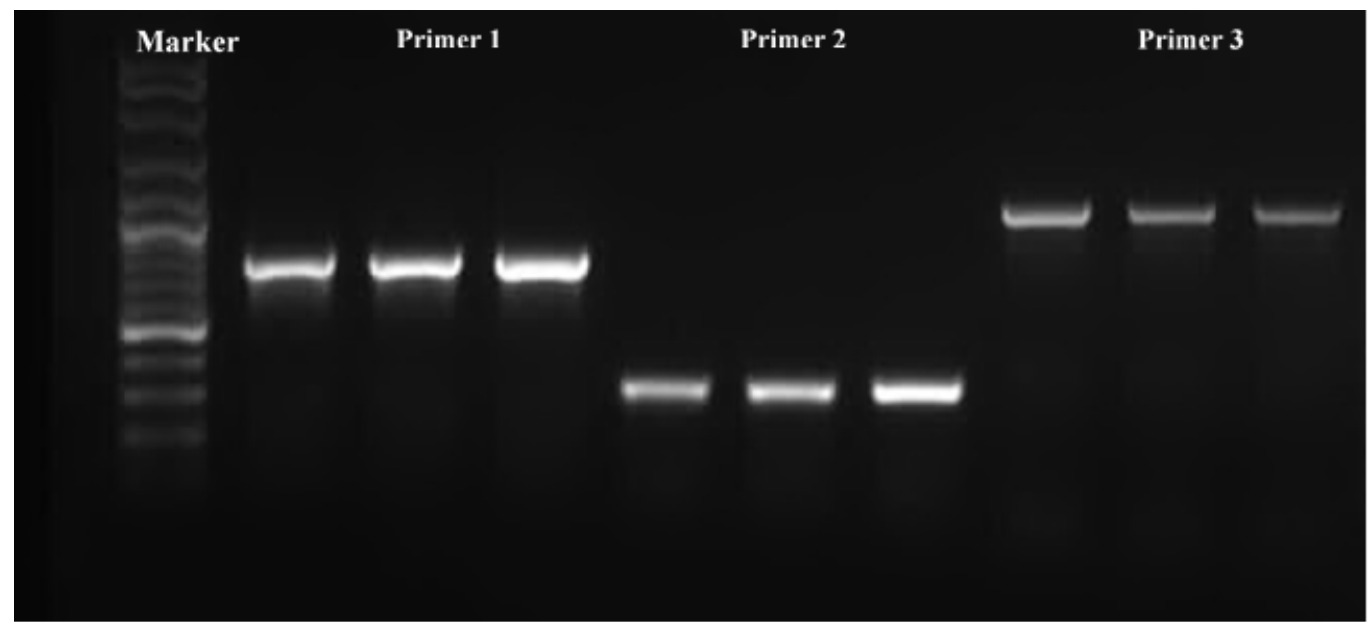

Figure 1 PCR product of the mlrA gene of Novosphingobium sp. KKU25s with specific primer design.

\section{Cloning and expression of the mlrA gene of KKU25s}

The mlrA gene of Novosphingobium sp. KKU25s, with an expected size of approximately 752 base pairs, was amplified using primer 1 and ligated into the pGEM-T cloning vector. pGEM-T-KKU25s-mlrA was confirmed by DNA sequencing. Then, pGEM-T-KKU25s-mlrA was digested by 2 endonucleases (BamHI and XhoI) and ligated to an expression vector; the resulting product was designated as the recombinant pET32a-KKU25s-mlrA plasmid. The insertion of the mlrA gene of Novosphingobium sp. KKU25s into pET32a was confirmed by sequencing, and the plasmid was successfully transformed into E. coli BL21 (DE3) to produce the recombinant pET32a-KKU25s-mlrA-BL21 bacteria. The inserted mlrA originating from the KKU25s strain had an open reading frame (ORF) of 752 nucleotides and encoded a putative protein of 251 amino acid residues (Figure 2). Its nucleotide sequence showed $98 \%$ similarity to the mlrA gene of Sphingomonas sp. ACM-3962 (GenBank accession No.: AF411068). After the recombinant bacteria were induced by IPTG, a protein product with a molecular weight of $22 \mathrm{kDa}$ was observed by SDS-PAGE (Figure 3). 


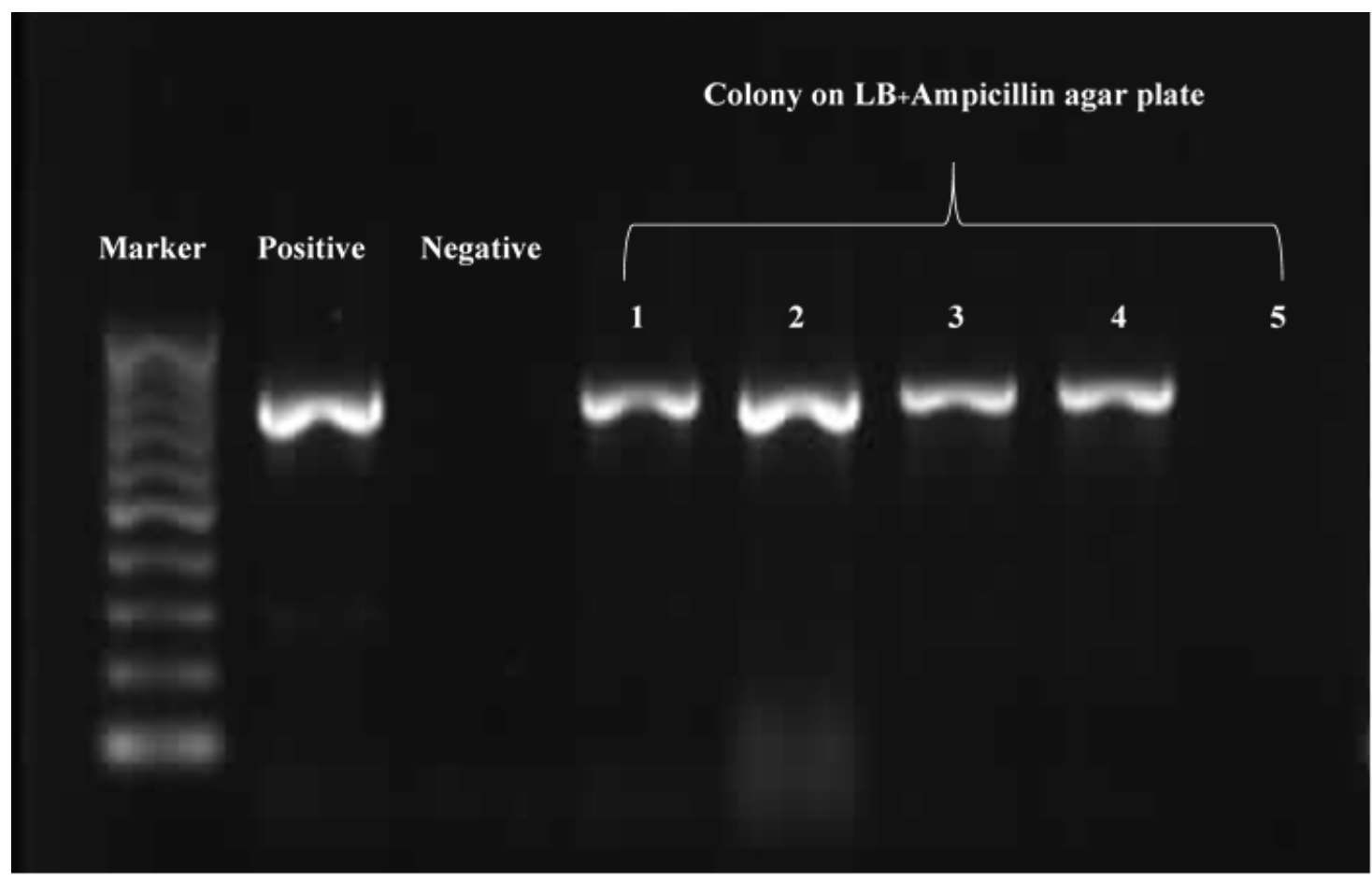

Figure 2 PCR product of the recombinant mlrA gene of approximately $752 \mathrm{bp}$ amplified using primer 1.

To investigate the protein homology of the deduced amino acid sequences of the mlrA gene of Novosphingobium sp. KKU25s, the putative amino acid sequence was analyzed against protein databases. BLASTP analysis demonstrated that the putative MlrA protein of the bacterial isolate KKU25s exhibited the highest similarity to the corresponding CPBP family intramembrane metalloproteases of Novosphingobium sp. THN1 (WP118074287) and Novosphingobium sp. MD-1 (WP125955355), with 99 $\%$ sequence similarity. The deduced amino acid sequence of the putative MlrA protein was identified as the abortive infection protein (Abi) or CAAX protease self-immunity. Multiple sequence alignment of the putative MlrA protein from Novosphingobium sp. KKU25s with its homologous proteins and the selected Abi proteins revealed the conserved amino acids $\mathrm{E}_{82} \mathrm{E}_{83} \mathrm{P}_{100} \mathrm{H}_{169} \mathrm{R}_{171} \mathrm{H}_{172}$ (the letters represent the type of amino acid; the numbers represent the position of the amino acid in the putative protein sequence) (sequence alignment not shown). From this alignment, it could be determined that all proteins contained 2 glutamic acid residues and 2 histidine resides, corresponding to the highly conserved Glu-Glu and histidine motifs of the Abi and CAAX proteins. In addition, the MlrA proteins contained a short amino acid sequence with 2 histidine residues and 1 glutamate residue $\left(\mathrm{H}_{177} \mathrm{AIH}_{180} \mathrm{NE}_{182} \mathrm{~L}\right)$, which is similar to a variant of the classic zinc-binding motif ( $\mathrm{HEXXH}$, in which $\mathrm{X}$ is any amino acid) found in a number of metalloprotease families [15,31]. 


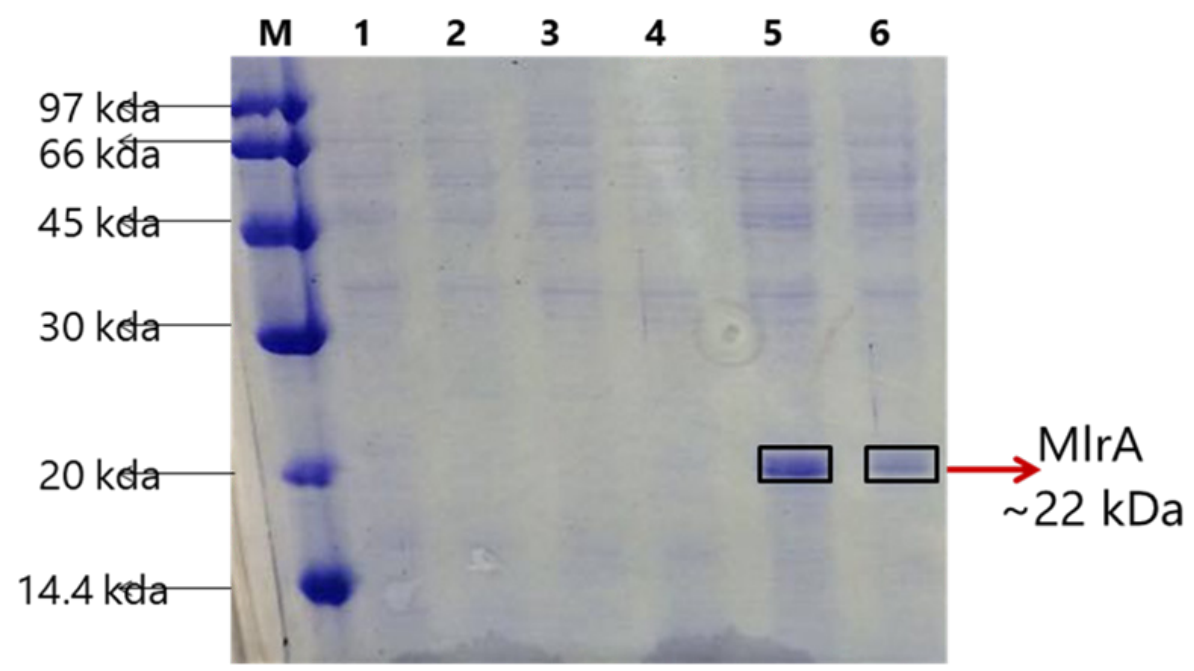

Figure 3 SDS-PAGE analysis of the supernatant containing the MlrA protein.

\section{Assessment of MC degradation by recombinant bacteria by HPLC and LC-MS analysis}

The degradation activity of the cell lysate of E. coli BL21 (De3) host cells expressing mlrA was investigated in bacterial degradation of $\left[\mathrm{Dha}^{7}\right] \mathrm{MC}-\mathrm{LR}$ using HPLC.

Beginning at $6 \mathrm{~h}$, the degradation byproduct was detected, and the [Dha $\left.{ }^{7}\right] \mathrm{MC}-\mathrm{LR}$ concentration began to decline. The degradation byproduct increased over time. At $12 \mathrm{~h}$ of incubation, the toxins were degraded by approximately $50 \%$, and the toxins were completely degraded (including byproduct A) after $30 \mathrm{~h}$ of incubation (HPLC chromatogram not shown). The byproduct was further investigated using LCMS, and MS analysis showed 2 main ion peaks. The ion at $m / z 981.50$ was consistent with [Dha ${ }^{7}$ MC-LR in its cyclic structure, whereas the ion at $\mathrm{m} / \mathrm{z} 999.51$ confirmed the degradation of MC (Figure 4) and was a linearized peptide fragment of $\left[\mathrm{Dha}^{7}\right] \mathrm{MC}-\mathrm{LR}$. The activity of mlrA from KKU25s-recombinant could degrade $\left[\mathrm{Dha}^{7}\right] \mathrm{MC}-\mathrm{LR}$, indicating successful expression.

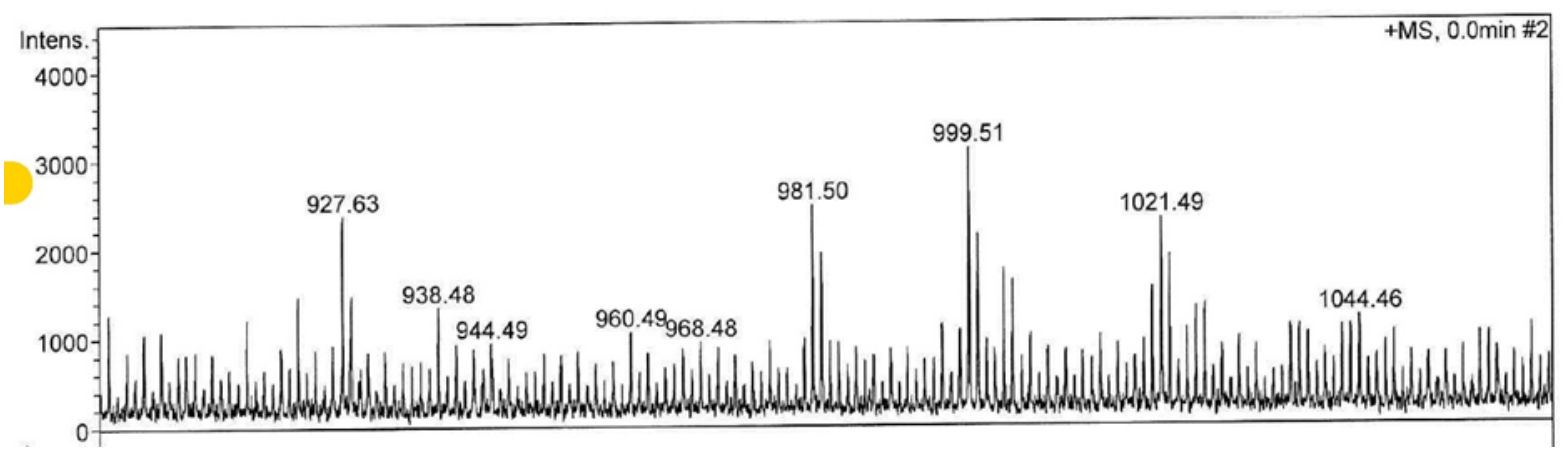

Figure 4 LC-MS spectrum of [Dha ${ }^{7}$ MC-LR degradation. A is [Dha ${ }^{7}$ MC-LR at $m / z$ 981.50, and $\mathbf{B}$ is the degradation byproduct at $m / z$ 999.50. 


\section{D structure modeling analysis}

The 3-dimensional structure of the MlrA protein, or microcystinase, of strain KKU25s was predicted based on the translation of the nucleotide sequence of KKU25s-mlrA into amino acid residues. The 3D structure models of KKU25s-mlrA were created using 2 bioinformatic programs, SWISSMODEL and Phyre2, for comparison.

The 3D structural model was predicted by the SWISS-MODEL program. A comparable protein template was found to be RCE1 (PDB ID 4cad.3.C). The template shared $25.01 \%$ sequence homology with KKU25s-mlrA. The KKU25s-mlrA model showed the presence of highly conserved alpha-helices and loop structures containing 4 conserved sequences: The $1^{\text {st }}$ sequence consisted of a range of amino acid sequences from $\mathrm{Gly}_{4}$ to $\mathrm{Lys}_{23}$; the $2^{\text {nd }}$ sequence consisted of $\mathrm{PrO}_{26}$ to $\mathrm{Leu}_{46}$; the $3^{\text {rd }}$ sequence consisted of $\mathrm{Ser}_{51}$ to $\mathrm{Lys}_{84}$; and the $4^{\text {th }}$ sequence consisted of $\mathrm{Met}_{89}$ to $\mathrm{His}_{98}$ (Figure 5).
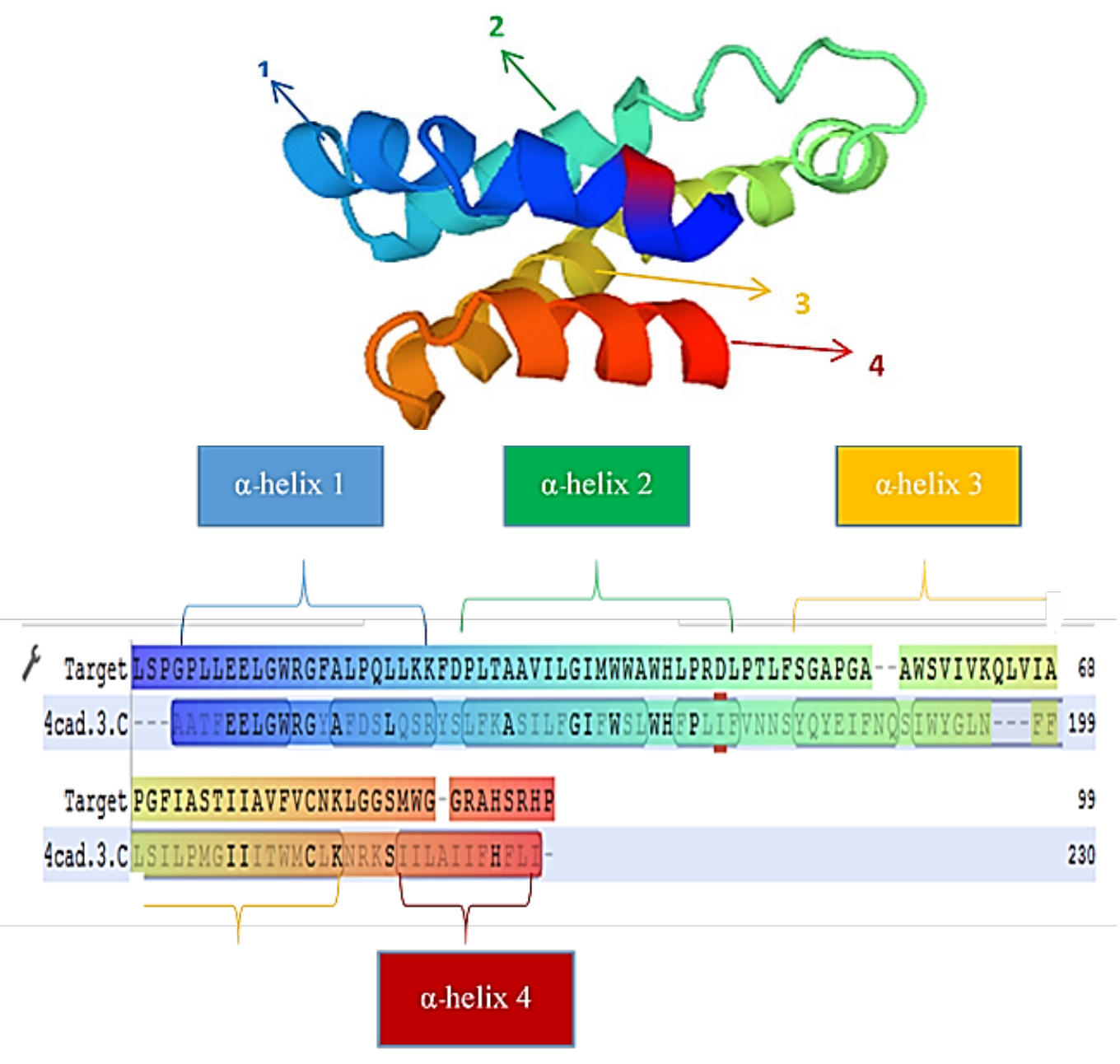

Figure 5 3D structure model and loop structures of KKU25s-mlrA (a) and highly conserved alpha-helices containing 4 conserved sequences (b) in the SWISS-MODEL program. 
For the prediction of mlrA using the Phyre2 program, the protein template was RCE1 (PDB ID $\mathrm{c} 4 \mathrm{cad})$, which is the same protein template used for comparison with the SWISS-MODEL program. The KKU25s-mlrA 3D structure model was also found to exhibit 4 highly conserved alpha-helices and loop structures (Figure 6). The sequence alignment of KKU25s-mlrA with the template protein revealed that the 2 structures shared $26 \%$ sequence identity. This result indicated that the model protein structures predicted by the 2 models were consistent.

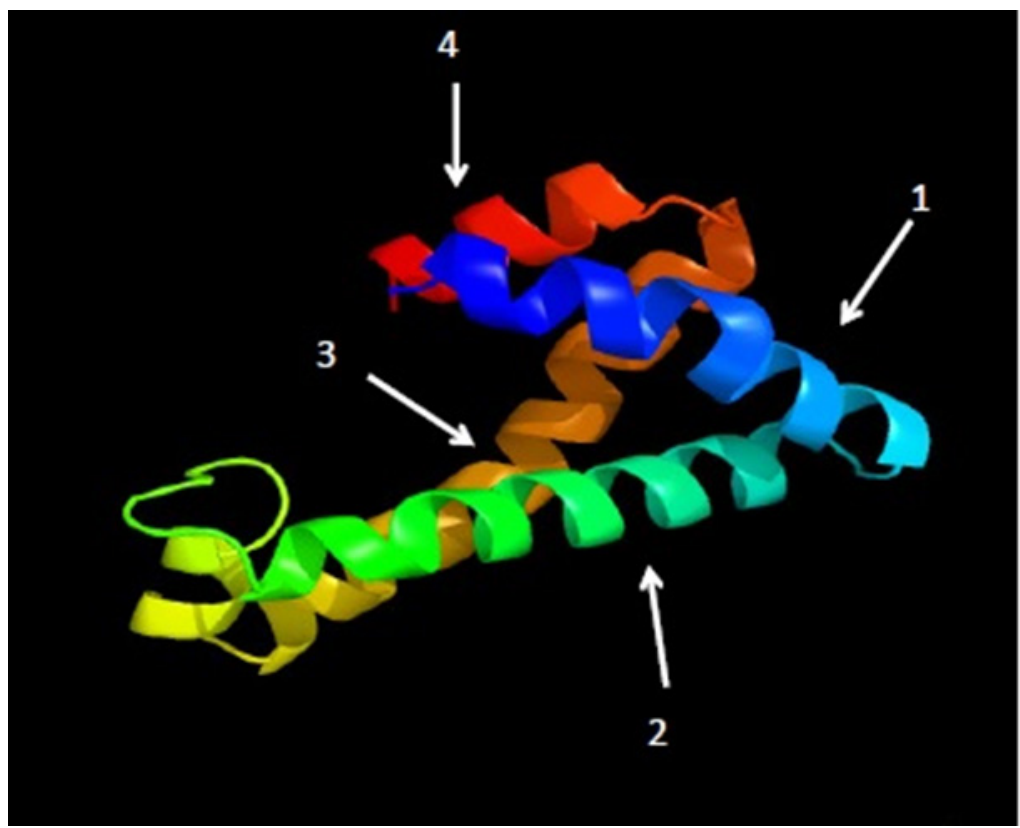

Figure 6 3D structure model of KKU25s-mlrA generated with the Phyre2 program.

\section{Discussion}

The presence of MCs in freshwater is an increasing problem and poses a potential threat to human and animal health worldwide. These toxins are well recognized as stable and persistent compounds; however, many reports have shown that MCs are vulnerable to breakdown by indigenous bacteria [25,26]. These bacteria have been shown to be species belonging to genera such as Bacillus, Burkholderia, Novosphingobium, Paucibacter Pseudomonas, Sphingomonas, Sphingopyxis, Sphingosinicella, and Stenotrophomonas $[13,27,28]$ as well as Novosphingobium sp. KKU25s, which was previously isolated by Phujomjai et al. [10] and used in his study. Therefore, there is great potential for cyanotoxin-degrading bacteria to be used for the removal of MCs from water, because biodegradation is a safe and natural treatment method for removing MCs from water. This study is the first to demonstrate the characterization of an MC-degrading enzyme against the $\left[\mathrm{Dha}^{7}\right] \mathrm{MC}-\mathrm{LR}$ variant rather than MC-LR, MC$\mathrm{RR}$ and MC-YR, which are the most common MCs detected in freshwater.

The MC degradation process was first characterized in Sphingomonas strain ACM-3962 (MJ-PV) in the degradation of MC-LR [14]. At least 3 intracellular hydrolytic enzymes are involved in this degradation process. The $1^{\text {st }}$ enzyme in the degradation pathway, a metalloprotease known as microcystinase, cleaves the aromatic ring of MC-LR, yielding a linearized MC-LR. Next, a serine peptidase catalyzes the linearized MC-LR, producing a tetrapeptide. Finally, the $3^{\text {rd }}$ enzyme, another metalloprotease, cuts the peptide bonds randomly, resulting in undetectable peptide fragments and amino acids [14]. To further understand the mechanism of MC-degrading enzymes, Bourne et al. [15] performed 
the cloning and molecular characterization of 4 genes from Sphingomonas strain ACM-3962 to identify the MC-degrading gene cluster, which consists of mlrA, mlrB, mlrC and mlrD. The mlrA, mlrB, and $\mathrm{mlrC}$ genes encode 3 peptidases, while the mlrD gene is predicted to encode a transport protein [15,27]. In this study, the mlrA gene, which encodes the MlrA protein, was amplified from the genomic DNA of Novosphingobium sp. KKU25s. The nucleotide sequencing of MlrA revealed that the deduced amino acid sequence of the putative MlrA protein from isolate KKU25s was identical to those of metalloproteases from Novosphingobium sp. THN1 and Novosphingobium sp. MD-1 [28]. The putative MlrA protein of isolate KKU25s was identified as a putative endometalloprotease on the basis of protein homology to the putative CAAX amino terminal protease family protein (a superfamily of putative membrane-bound metalloproteases) similar to the putative MlrA protein of Sphingomonas strain MD-1 [29]. The putative MlrA protein of isolate KKU25s was also identified as a zinc-dependent metalloprotease on the basis of 2 histidine residues and a glutamate residue (HXXHXE) in a sequence similar to the putative MlrA protein of the Sphingomonas strain ACM-3962 [15]. Therefore, the putative MlrA protein of isolate KKU25s is most likely to be a zinc endometalloprotease similar to the MlrA proteins of strains THN1 and MD-1.

The mechanism by which the putative MlrA protein of isolate KKU25s hydrolyzes [Dha ${ }^{7}$ ] MC-LR is probably similar to that of the MlrA protein of Sphingomonas strain ACM-3962 that cleaves MC-LR because they contain identical active sites (VLTHAIHNE) (where the $2 \mathrm{Hs}$ are zinc ligands, and E is the active site residue involved in catalytic activity) [15,30]. In this study, based on the detected byproducts, at least 3 hydrolytic enzymes are involved in this pathway. The $1^{\text {st }}$ enzyme, mlrA, catalyses the cleavage of the aromatic ring of [Dha ${ }^{7}$ ] MC-LR (cyclo-Ala-Leu-MeAsp-Arg-Adda-Glu-Dha; MW = 981), yielding linearized peptides $\left(\mathrm{NH}_{2}\right.$-Adda-D-Glu-Dha-D-Ala-L-Leu-D-MeAsp-L-Arg-OH; $\mathrm{MW}=999$ ) (byproduct A). The $2^{\text {nd }}$ enzyme cuts linearized (acryclo-) $\left[\mathrm{Dha}^{7}\right] \mathrm{MC}-\mathrm{LR}$ at the alanine-leucine peptide bond, producing a tetrapeptide (byproduct B), and, finally, the third enzyme presumably cleaves other bonds, producing undetectable or unidentified peptide fragments. This enzymatic pathway is identical to that previously identified by Bourne et al. [15]. It is interesting that among the different amino acids of the 2 MlrA proteins, there is some similarity regarding which 2 of the nonpolar amino acids isoleucine and leucine and the polar amino acids alanine and glycine align. The amino acids that differ between the 2 proteins may not affect the ability of the proteins to hydrolyze MCs because the conserved active site is unchanged. Moreover, the presence of a signal peptide sequence that is conserved between the ACM3962 and KKU25s strains implies that the degradation of peptides by these bacteria occurs in the periplasmic space of the cells [15,31].

The expression of the mlrA gene in E. coli BL21 (DE3) was successful. Recombinant KKU25smlrA, encoding microcystinase (mlrA) or the KKU25s-mlrA enzyme, was capable of degrading [Dha ${ }^{7}$ ] MC-LR at $30 \mathrm{mg} \mathrm{L}^{-1}$ within just $30 \mathrm{~h}$. Using liquid chromatography-tandem mass spectrometry (LCMS), linearized peptides of $\left[\mathrm{Dha}^{7}\right] \mathrm{MC}-\mathrm{LR}$ were detected. The intermediate product suggested that the mlrA enzyme cleaved the aromatic ring of [Dha $\left.{ }^{7}\right] \mathrm{MC}-\mathrm{LR}\left(\mathrm{NH}_{2}\right.$-Adda-D-Glu-Dha-D-Ala-L-Leu-D-MeAsp-LArg-OH) $(\mathrm{MW}=981)$ at the Adda-arginine peptide bond, yielding linearized peptides $\left(\mathrm{NH}_{2}\right.$-Adda-D-GluDha-D-Ala-L-Leu-D-MeAsp-L-Arg-OH; MW =999). The linearized peptides of [Dha ${ }^{7}$ MC-LR were subsequently degraded by peptidase and metallopeptidase enzymes to form small peptides. This enzymatic pathway is identical to that identified by others [14,21,24,26,27]. It is important to note that the intermediate MC degradation products of the linearized peptides, the tetrapeptide and the digested amino acids are significantly less toxic than the parent MC molecules. Bourne et al. [14] demonstrated that the toxicity of the linearized peptides of MC-LR was reduced 160-fold compared with the parent compound, while other studies have demonstrated that the tetrapeptide and digested amino acids are nontoxic [12,27]. These findings strongly indicate that microbial degradation is a potentially safe and natural treatment for the removal of MCs from water [10,12].

Only 1 study on the 3-dimensional (3D) structure of microcystinase has been conducted [25]. The authors found that the structure of the MlrA protein ADK25053 from Sphingomonas sp. USTB-05 belongs to the CPBP family intramembrane metalloprotease, similar to type II CAAX prenyl protease, whereas KKU25s-mlrA 3D models revealed that mlrA contains 4 alpha helical structures and is 
homologous to a member of the type II CAAX prenyl proteases. Although, the RCE1 protein shows less identity to KKU25s-mlrA, RCE1 and mlrA are relevant because RCE1 is an integral membrane protease similar to mlrA. RCE1 possesses the same CAAX protease as microcystinase. This work is valuable for understanding the mechanism of $\left[\mathrm{Dha}^{7}\right] \mathrm{MC}-\mathrm{LR}$ degradation by mlrA and may be useful for the applications aimed at the removal of MCs in freshwater environments.

The potential for biological processes to remove MCs in water treatment plants has stimulated significant research in this area. A range of small-scale experiments have been carried out using bacteria to degrade MC-contaminated water in which the bacterial cells are immobilized (i) on polyester resin in a small-scale bioreactor [32], (ii) in biologically granular activated carbon columns [33] and (iii) in biologically active sand filters [34]. These biological degradation methods were successful in completely removing MCs from contaminated water and present potential for the larger-scale applications. However, some factors of potential for bioprocess in removing MCs on real environments are required to further investigate, including (1) how bioprocess could be physically adapted in treatment plants, (2) the efficacy, volume of water that could be treated, duration of treatment and cost of a adapted bioprocess design, (3) how KKU25s will perform and react in the actual environment where a wide range of substrate compounds exist, (4) whether or not the bacteria are stable in the field and perform the same biodegradation processes as noted in the laboratory, (5) difficulties associated with stimulating bacterial growth in the field, and (6) other factors that might reduce the degradation activity of KKU25s in the environment.

\section{Conclusions}

The bacterial strain KKU25s-mlrA encodes the microcystinase (MlrA) enzyme responsible for the biodegradation of [ $\mathrm{Dha}^{7}$ ] MC-LR. We cloned the mlrA gene from Novosphingobium sp. KKU25s into the pGEM-T cloning vector. The nucleotide sequence of KKU25s-mlrA (752 bp) was $98 \%$ similar to the mlrA gene of Sphingomonas sp. ACM-3962. Recombinant KKU25s-mlrA in the pET32a expression vector was expressed when induced with IPTG. The mlrA enzyme is approximately $22 \mathrm{kDa}$ according to SDS-PAGE. The mlrA of KKU25s could degrade [Dha $\left.{ }^{7}\right]$ MC-LR. The 3-dimensional (3D) model structure of KKU25s-mlrA was analyzed based on the putative amino acid sequence deduced from the mlrA gene sequence by the SWISS-MODEL and Phyre2 programs. The 3D structure of KKU25s-mlrA consisted of an alpha-helical structure at the 4 position. The amino acid sequence of the alpha helix corresponded to the corresponding position range according to both programs. By predicting the 3dimensional structure, it was determined that the protein was similar to the CAAX protease.

\section{References}

[1] A Zyska and J Jasik-Ślęza. Mechanism and effects of cyanobacterial hepatotoxin action on human organism. Pol. J. Public Health 2014; 124, 156-9.

[2] N Butler, JC Carlisle, R Linville and B Washburn. Microcystins: A brief overview of their toxicity and effects, with special reference to fish, wildlife, and livestock. California Environmental Protection Agency, Sacramento, USA, 2009, p. 1-17.

[3] M Rex. Is protein phosphatase inhibition responsible for the toxic effects of okadaic acid in animals? Toxins 2013; 2, 267-85.

[4] I Trevino-Garrison, J DeMent, FS Ahmed, P Haines-Lieber, T Langer, H Ménager, J Neff, van der D Merwe and E Carney. Human illnesses and animal deaths associated with freshwater harmful algal blooms-Kansas. Toxins 2015; 2, 353-66.

[5] RP Rastogi, RP Sinha and A Incharoensakdi. The cyanotoxin-microcystins: Current overview. Rev. Environ. Sci. Biotechnol. 2014; 13, 215-49.

[6] RW Zurawell, H Chen, JM Burke and EE Prepas. Hepatotoxic cyanobacteria: A review of the biological importance of microcystins in freshwater environments. J. Toxicol. Environ. Health B Crit. Rev. 2005; 8, 1-37. 
[7] SJ Hoeger, BC Hitzfeld and DR Dietrich. Occurrence and elimination of cyanobacterial toxins in drinking water treatment plants. Toxicol. Appl. Pharmacol. 2005; 203, 231-42.

[8] L Shang, M Feng, X Xu, F Liu, F Ke and W Li. Co-occurrence of microcystins and taste-and-odor compounds in drinking water source and their removal in a full-scale drinking water treatment plant. Toxins 2018; 1, 1-17.

[9] T Somdee, J Wibuloutai, TD Somdee and A Somdee. Biodegradation of the cyanobacterial hepatotoxin $\left[\mathrm{Dha}^{7}\right]$ MC-LR within a biologically active sand filter. Water Sci. Technol. Water Supply 2014; 4, 672-80.

[10] Y Phujomjai, A Somdee and T Somdee. Biodegradation of microcystin [ $\left.\mathrm{Dha}^{7}\right] \mathrm{MC}-\mathrm{LR}$ by a novel microcystin-degrading bacterium in an internal airlift loop bioreactor. Water Sci. Tech. 2016; 73, 26774.

[11] K Christoffersen, S Lyck and A Winding. Microbial activity and bacterial community structure during degradation of microcystins. Aquat. Microb. Ecol. 2002; 27, 125-36.

[12] $\mathrm{J} \mathrm{Li}, \mathrm{R} \mathrm{Li}$ and $\mathrm{JLi}$. Current research scenario for microcystins biodegradation: A review on fundamental knowledge, application prospects and challenges. Sci. Total. Environ. 2017; 595, 615-32.

[13] P Kumar, K Hedge, SK Brar, M Cledon and A Kermanshahi-pour. Potential of biological approaches for cyanotoxin removal from drinking water: A review. Ecotox. Environ. Saf. 2019; 172, 488-503.

[14] DG Bourne, RL Blakeley, GJ Jones, A Jones, AP Negri and P Riddles. Enzymatic pathway for the acterial degradation of cyanobacterial cyclic peptide toxin microcystin-LR. Appl.Environ. Microbiol. 1996; 62, 4086-94.

[15] DG Bourne, W Smith, GJ Jones and P Riddles. Characterization of a gene cluster involved in bacterial degradation of the cyanobacterial toxin microcystin-LR. Environ. Toxicol. 2001; 16, 52334.

[16] Y Peerapornpisal, W Sonthichai, M Suchotiratana, S Lipigorngoson, W Ruangyuttikarn, K Ruangrit, J Pekkoh, R Prommana, N Panuvanitchakorn, N Ngearnpat, S Kiatpradub and S Promkutkaew. Survey and monitoring of toxic cyanobacteria in water supplied and fisheries in Thailand. Chiang Mai J. Sci. 2002; 29, 71-9.

[17] R Prommana, Y Peerapornpisal, N Whangchai, LF Morrison, JS Metcalf, W Ruangyuttikarn, A Towproma and GA Codd. Microcystins in cyanobacterial blooms from two freshwater prawn (Macrobrachium rosenbergii) ponds in Northern Thailand. Sci. Asia 2006; 32, 365-70.

[18] T Somdee, T Kaewsan and A Somdee. Monitoring toxic cyanobacteria and cyanotoxins (microcystins and cylindrospermopsins) in four recreational reservoirs (Khon Kaen, Thailand). Environ. Monit. Assess. 2013; 185, 9521-9.

[19] S Ruangsomboon, W Yongmanitchai, P Taveekijakarn and M Ganmanee. Cyanobacterial composition and microcystin accumulation in catfish pond. Chiang Mai J. Sci. 2014; 41, 27-38.

[20] K Moolwangand and T Somdee. Purification of cyanobacterial toxin, microcystins, by DEAE and Strata-X SPE chromatography. KKU Sci. J. 2019; 47, 26-33.

[21] EML Janssen. Cyanobacterial peptides beyond microcystins: A review on co-occurrence, toxicity, and challenges for risk assessment. Water Res. 2019; 151, 488-99.

[22] JJ Doyle and JL Doyle. Isolation of plant DNA from fresh tissue. Focus 1990; 12, 13-5.

[23] YF Cheng, $\mathrm{CH}$ Yang and WH Liu. Cloning and expression of Thermobifida xylanase gene in the methylotrophic yeast Pichia pastoris. Enzyme Microb. Technol. 2005; 37, 541-6.

[24] J Sambrook and DW Russell. Purification of nucleic acids by extraction with phenol: Chloroform. CSH Protoc. 2006; 1, 169-70.

[25] H Xu, H Wang, Q Xu, L Lv, C Yin, X Liu, H Du and H Yan. Pathway for biodegrading microcystin-YR by Sphingopyxis sp. USTB-05. PLoS One 2015; 10, e0124425.

[26] J Dexter, D Dziga, J Lv, J Zhu, W Strzalka, A Maksylewicz, M Maroszek, S Marek and P Fu. Heterologous expression of mlrA in a photoautotrophic host-engineering cyanobacteria to degrade microcystins. Environ. Pollut. 2018; 237, 926-35.

[27] D Dziga, M Wasylewski, B Wladyka, S Nybom and J Meriluoto. Microbial degradation of microcystins. Chem. Res. Toxicol. 2013; 26, 841-52. 
[28] R Wang, J Li, Y Jiang, Z Lu, R Li and J Li. Heterologous expression of mlrA gene originated from Novosphingobium sp. THN1 to degrade microcystin-RR and identify the first step involved in degradation pathway. Chemosphere 2017 ; 184, 159-67.

[29] T Saito, K Okano, HD Park, T Itayama, Y Inamori, BA Neilan, BP Burns and N Sugiura. Detection and sequencing of the microcystin LR-degrading gene, mlrA, from new bacteria isolated from Japanese lakes. FEMS Microbiol. Lett. 2003; 229, 271-6.

[30] H Yan, W Wei, J Chen, J Wang and H Wang. Characterization of the first step involved in enzymatic pathway for microcystin-RR biodegraded by Sphingopyxis sp. USTB-05. Chemosphere 2012; 87, 12-8.

[31] D Dziga, B Wladyka, G Zielinska, J Meriluoto and M Wasylewski. Heterologous expression and characterization of microcystinase. Toxicon 2012; 59, 578-86.

[32] K Tsuji, M Asakawa, Y Anzai, T Sumino and KI Harada. Degradation of microcystins using immobilized microorganism isolated in an eutrophic lake. Chemosphere 2006; 65, 117-24.

[33] H Wang, L Ho, DM Lewis, JD Brookes and G Newcombe. Discriminating and assessing adsorption and biodegradation removal mechanisms during granular activated carbon filtration of microcystin toxins. Water Res. 2007; 41, 4262-70.

[34] L Ho, D Hoefel, CP Saint and G Newcombe. Isolation and identification of a novel microcystin degrading bacterium from a biological sand filter. Water Res. 2007; 41, 4685-46. 